Fecha de recepción: junio 2020

Fecha de aceptación: agosto 2020

Versión final: septiembre 2020

\section{Design cidadão: abordagens para a vivência urbana}

Anderson Antonio Horta ${ }^{(1)}$, Clara Santana Lins Cerqueira ${ }^{(2)}$, Mylene Fernandes Batista ${ }^{(3)}$ e Rita Aparecida da Conceição Ribeiro ${ }^{(4)}$

Resumo: A participação cidadã no espaço público urbano pode ser incentivada pela atividade do design, contrapondo-se à manipulação de forças dominantes que modelam a usabilidade das cidades e criam padrões segregativos. Designers, conscientes de sua responsabilidade social e através de uma visão humanista, modificam o arranjo espacial e o sentimento de pertencimento dos indivíduos, ou seja, objetos, mensagens, sistemas e experiências se configuram como potencializadores da dinâmica do cotidiano urbano e da afirmação do direito à cidade. O presente artigo explora o conceito experiência da alteridade como um caminho ou inspiração que intercede as práticas de design, sendo essas práticas exploradas neste trabalho pela atuação do Coletivo Micrópolis, em projeto de intervenção no bairro Calafate, Belo Horizonte, Brasil, na breve análise do impacto das instalações de varandas urbanas nas ruas e calçadas da cidade, no qual se descrevem atributos direcionados ao uso de mobiliário inclusivo e descrição de projeto de design, intitulado Borrachalioteca Sobre Rodas (BSR), divulgado e implementado para a comunidade de Sabará, Brasil. O intuito deste trabalho é incitar a reflexão dos atuais diálogos sobre a vivência e a humanização da cidade.

Palavras chave: design - espaço urbano - direito à cidade - experiência - intervenções.

[Resumos em espanhol e inglês nas páginas 202-203]

(1) Designer, Doutor, Professor pesquisador do Centro Universitário de Belo Horizonte UniBH, Brasil.

(2) Designer, Mestre em Design, Professora na Universidade do Estado de Minas Gerais UEMG, Brasil. Bolsista do CNPq.

(3) Designer, bolsista Capes e mestranda no Programa de Pós-graduação em Design Da Universidade do Estado de Minas Gerais - UEMG, Brasil.

(4) Doutora, Professora e Pesquisadora do Programa de Pós-graduação em Design Da Universidade do Estado de Minas Gerais - UEMG, Brasil. Líder do Grupo de Pesquisa Design \& Representações Sociais. Bolsista FAPEMIG. 


\section{Introdução}

As relações de convívio nas cidades de hoje estão polarizadas. Ocorrem aberturas e oportunidades ao diálogo da participação cidadã e democrática, a partir de esferas políticas independentes e conscientes do papel da diversidade social para a vivência urbana, à medida que se desenvolve o processo de espetacularização da cidade por parte de domínios públicos e privados, voltado para o consumo da experiência. Em geral, são processos divergentes que fortalecem as intervenções de cunho social, político e cultural. Este estudo é um retrato da articulação do design e os meios de produção e reprodução da dinâmica urbana voltada ao direito à cidade e resistência à lógica do capital, baseada no poder de resistência e resgate da cidadania promovido por atores sociais.

A relação do design e espaço urbano está na responsabilidade social da profissão. Para o exercício da cidadania é necessário que haja informação disponível, que, para tanto, pode ser potencializada através das habilidades do designer, uma vez que ele se configura como mediador entre o indivíduo e a sociedade na divulgação e acesso ao conhecimento público, por meio de informações inteligíveis, que permitam a interpretação de mensagens por meio da subjetividade, uma vez que o receptor é quem traduz o conteúdo da mensagem, na forma como essas mensagens são transmitidas e o tempo dessa transmissão. Esses atributos influenciam o fortalecimento ou enfraquecimento da noção de cidadania.

O trabalho foi elaborado através de estudo teórico e exploratório acerca do tema apresentado e estruturado em três partes, tendo como objeto empírico as intervenções urbanas. A primeira parte enfatiza que a construção da identidade influencia na participação cidadã e justifica o papel do design para a transformação social do espaço urbano. Diante disso, a segunda parte apresenta o conceito de experiência da alteridade e relaciona seus fundamentos aos objetivos de design. Perpassa pelo entendimento de que é um instrumento exploratório e um caminho que intercede as práticas de design. Comparando, é uma fase de reconhecimento e interpretação. Na terceira parte são apresentados exemplos práticos do papel do design para melhorar o convívio social no espaço urbano e promover a integração e a diversidade de atividades e pessoas.

\section{Design e participação cidadã para o convívio social}

Frequentes estudos sobre urbanidade discutem a condição cultural e social do espaço público da cidade para viabilizar manifestações de cidadania. O indivíduo ao vivenciar a cidade acumula referências culturais, mas também externa suas referências individuais, que compartilha no meio social. A partir dessa interação há o envolvimento social cotidiano em que o indivíduo percebe o outro e se identifica. Esse processo constrói a identidade coletiva e ajuda a entender as relações dentro desse coletivo.

É importante ressaltar que, a partir das relações coletivas, se instituem os discursos sobre o direito à cidade, sendo que ele é 
[...] muito mais do que um direito de acesso individual ou grupal aos recursos que a cidade incorpora: é um direito de mudar e reinventar a cidade mais de acordo com nossos mais profundos desejos. Além disso, é um direito mais coletivo do que individual, uma vez que reinventar a cidade depende inevitavelmente do exercício de um poder coletivo sobre o processo de urbanização (Harvey, 2014, p. 28).

O entendimento das implicações que resultam no discurso do direito à cidade remete a forma como ela é dividida por fatores financeiros ou de renda, no qual as desigualdades se concretizam no contexto do arranjo urbano. Dessa maneira as relações sociais podem também ser entendidas pelo distanciamento entre os indivíduos e as classes que se formam no processo de segregação.

E desse entendimento da configuração socioespacial podemos transpor para o exercício do Design, as influências de sua produção material nos processos de apropriação urbana. Todo produto de Design possui uma linguagem objetivada, um direcionamento. Está inserido num contexto espacial e temporal, passível de interpretação e significado, que o impossibilita ter um caráter neutro na cultura material (Latour, 2014). Uma ideia contrária a isso é responsável por distanciar o design de sua responsabilidade social.

A ideia de que os processos de design devem ser presididos por um sistema objetivo e despidos de qualquer subjetividade é responsável por ampliar sua distância de uma prática política. Se o objeto é neutro e está dado no mundo, cabendo ao Homem vê-lo, interpretá-lo ou "escrevê-lo em linguagem matemática", e o design nada mais seja que uma espécie de engenharia reversa desta forma "neutra" de observação e interpretação do mundo, deve ser neutro também o produto de design. Aqui o compromisso com a materialidade moderna passa ao largo da compreensão de que o próprio sensível é enformado por uma série de vetores perfeitamente históricos e políticos (Nogueira \& Portinari, 2016, p. 35).

Para Bonsiepe (2011), o designer, na atualidade, deve questionar sua atividade projetual. Na relação design e democracia, o autor expõe as falhas e o desgaste do design, assim como o desgaste do conceito de democracia. Na cultura ocidental e no contexto neoliberal, ela dita as relações sociais e condiciona o pensamento do homem. O desgaste do conceito de democracia é justamente limitar as potencialidades dos indivíduos enquanto participação cidadã. Com o intuito de pensar possibilidades para resolver esta questão, o designer, perante um posicionamento humanista, deve auxiliar e promover a consciência crítica para que a democracia não se limite a subordinação da sociedade através de um centro de poder.

No humanismo configura-se como exercício de nossas competências a compreensão, interpretação e empatia para lidar com as linguagens que comunicam mensagens e portam significados. Traduzindo para a ação projetual, é o exercício das capacidades projetuais para interpretar as necessidades dos indivíduos e grupos sociais, e elaborar propostas que solucionam suas demandas, pautadas pela viabilidade e o cunho social que lhes são intrín- 
secos. O designer deve possuir uma consciência crítica perante o desequilíbrio entre os eixos centro e periferia, pois, assim, podem-se explorar espaços alternativos capazes de uma modificação nas relações sociais. Espaços, que não impeçam a participação cidadã e que não tratem os indivíduos de acordo com sua condição social (Celaschi \& Moraes, 2013). A participação cidadã pode ser intensificada pela ação do designer, que em contato com as diferentes manifestações, comportamentos e discursos sociais reintegra o indivíduo como agente ativo no processo de pensar o espaço onde habita. Designers, em conjunto com outras áreas, podem facilitar o acesso do indivíduo à informação e comunicação, elementos estes, determinantes para o exercício da cidadania. O campo de atuação também permeia os níveis institucionais, à medida que possíveis colaborações na estrutura organizacional das instituições possam ser implementadas para contribuir com acesso digno ao conhecimento.

A participação cidadã impulsionada pela prática do design, e em trabalho conjunto a uma equipe multidisciplinar, fortalece a inclusão social. Por meio de práticas inovadoras, tecnológicas ou não, o cidadão pode construir seu cenário de atuação. Englobar o estudo de diferentes culturas, habilidades distintas e conhecimentos integrados por meio de uma visão sistêmica focada na solução de problemas complexos que englobem o contexto local são uma vertente do design. O exercício da democracia em uma sociedade, não deve, portanto, se basear em um contexto global, uma vez que cada cultura possui suas particularidades.

Ao relacionar design e produção do espaço urbano estamos ao mesmo tempo relacionando design e identidade urbana. Dessa forma, implica em compreender as possibilidades de atuação no que tange aos níveis de envolvimento na (re) qualificação urbana.

Ou seja, uma ponderação sobre a dimensão e influência cultural(izante) do design nas novas formulações da vida urbana, materializadas no uso e apropriação social das cidades, e desse modo, redesenhar comportamentos que concorram para a existência de fenómenos integrados de relação social (Paiva, 2012, p. 52).

Os espaços públicos urbanos se configuram como o cenário para o desempenho da vida pública. Refletem o trabalho e o lazer, a produção e o consumo, mas também são palcos das inseguranças e medos. Ou seja, na contemporaneidade a manipulação do espaço urbano depende de diferentes abordagens e áreas convergentes com objetivo de possibilitar o direito de uso e acesso aos cidadãos.

O design não é apenas uma actividade que produz objectos mas é também um processo que permite experienciar ideias. Este processo de entendimento e de comunicação entre o público e o espaço urbano, resulta em experiências significativas para o público que comunica e reage ao ambiente recriado pelo designer. O público é o alvo da experiência, logo deve ser colocado em primeiro lugar, denotando-se uma preocupação com a experiência humana e, com a sua integração no contexto social e cultural do espaço urbano. Para tal, o designer deve proceder a métodos de pesquisa que potenciem o desenvolvimento 
de comunicações efectivas, entre o objeto de experiência (espaço público) e o utilizador (Carvalho, Castela \& Oliveira, 2007-2008, p. 22).

Essa abordagem do design como agente de transformação social perpassa por aspectos relacionais na atual configuração social. A contemporaneidade trouxe à tona as questões da diversidade, da multiplicidade, o confronto e visões de mundo diferenciadas, as interações entre imaginários e culturas, novas construções materiais e simbólicas, multidimensionalidades, fragmentações, metamorfoses, hibridismo e a consciência ambiental (Moura, 2011). Todos esses elementos permeiam os atuais diálogos no cotidiano. A sua abrangência incorpora atitudes e desafios políticos, sociais, culturais a fim de se encontrar a maneira de projetar com mais consistência, de olho no mundo real.

Um dos compromissos que se espera do design com o espaço urbano, é a democratização das soluções, e nesse em particular, importa sublinhar o papel que tem vindo a promover no campo da usabilidade, permitindo o acesso por parte de diferentes perfis de utilizadores, o que na prática configurará a adopção de soluções aceites por um universo alargado de públicos, com condições, literacias, interesses e comportamentos distintos, na linha dos princípios do design universal (Paiva, 2012, p. 67).

Dessa forma, os objetos ao serem experimentados pelos indivíduos geram uma cultura material, e esta constrói identidades, representadas pela subjetividade dos indivíduos. O uso e funções, a estética e a forma, e o significado dos artefatos, são aspectos comunicacionais, que "transmitem conceitos que influenciam os modos de ser e de se relacionar. Muitos desses conceitos são replicados durante a atividade projetual, fazendo do designer um participante ativo no processo de construção das identidades" (Andrade, Barros, Lins \& Wanderley, 2017, p. 20). Portanto, entender como ocorrem as construções identitárias e de que forma são englobadas no sistema social, contribui para a prática projetual direcionada para um papel social, em que se possa influenciar os comportamentos que ainda segregam a sociedade.

\section{Experiência da alteridade como ferramenta para processo de design do urbano}

Podemos inferir que para o designer atuar como agente de transformação social de um local é necessário que esse profissional acumule referências associativas que o ajudarão a entender a cultura e a identidade local a fim de definir estratégias coerentes. Os métodos são amplos, podendo-se obter informações através de entrevistas, observações, mas de tal modo que não siga um caminho superficial. O design transita entre várias áreas do conhecimento e com isso pode-se identificar algumas relações com a prática da experiência da alteridade, também chamada de errância urbana, já utilizada por atores sociais, individual ou coletivamente, como forma de expressar a ruptura de um cotidiano automatizado e 
pouco perceptível. A prática é uma forma mais aprofundada, detalhada e complexa para se conhecer o contexto, a cultura e a memória de um grupo social ou de um local.

Errâncias urbanas podem demonstrar as maneiras pelas quais se evidenciam a participação cidadã e coletiva, de tal modo que evidenciem também mudanças significativas na estrutura local em nexo ao discurso do direito à cidade. Basicamente, errâncias urbanas são práticas de percepção e intervenção na cidade através da experiência da alteridade. $\mathrm{O}$ ato de perceber a cidade através da consciência do lugar assume papel fundamental na quebra de paradigmas vigentes que não deixam que o potencial da cidade se desenvolva. Ao errante cabe reconhecer os elementos da paisagem urbana e da dinâmica social. Perceber as potencialidades e reconhecer que a vitalidade da cidade depende da experiência e da diversidade de pessoas, de usos e interações. O foco de pensamento está na cidade real, não mais na cidade ideal e no planejamento urbano tradicional. Ou seja, assistimos ao crescimento do empoderamento e participação da comunidade em políticas sociais, as rupturas no cotidiano, por sujeitos que experimentam habitar a cidade gerando "perturbações" para a rotina. Modifica o protagonismo, a usabilidade e consumo no espaço urbano com foco na sustentabilidade social da cidade.

A experiência errática, assim pensada como ferramenta, é um exercício de afastamento voluntário do lugar mais familiar e cotidiano, em busca de uma condição de estranhamento, em busca de uma alteridade radical. O errante, ao buscar o estranho no cotidiano familiar, vai de encontro a essa alteridade e, assim, instaura o dissenso, que é precisamente o pressuposto básico que possibilita a constituição de qualquer esfera pública. A experiência errática é uma possibilidade de experiência da alteridade na cidade (Jacques, 2012, p. 48).

Essa experiência do fazer diferente, da alteridade na cidade diverge do processo atual de espetacularização urbana, pois expõe as realidades que ele busca esconder ou eliminar através de projetos de assepsia urbana, gentrificação, vigilância e controle urbano. A abordagem da espetacularização urbana contemporânea já se tornou recorrente no meio acadêmico, retratando a cidade atual sob a perspectiva de um espetáculo. É um processo que transforma a cidade em uma estratégia de marketing, para construir uma imagem internacional com apelo turístico e cultural, garantindo reconhecimento e lugar na geopolítica global. É pensado como um modelo de consumo abarcado pela estetização da realidade da vida cotidiana no espaço urbano, ou seja, "[...] redução de sua diversidade, a uma "domesticação" da complexidade e ao afastamento de qualquer "negatividade", com a finalidade de moldar melhor os cenários a um consumo global por parte dos cidadãosturistas" (Castriota, 2010, Seção A cidade das vivências, para. 24).

Para explorar maneiras de contornar isso, pesquisadores buscam suporte em literaturas que explorem o conceito da experiência errática da cidade, que consiste na ação de resistência aos padrões hegemônicos por parte de indivíduos que buscam desestabilizar essa estetização e os usos planejados com fins midiáticos. Nas narrativas dos errantes, como são chamados os indivíduos que experimentam a cidade na busca da alteridade urbana, são apresentadas três maneiras possíveis para tal ação: a capacidade de se perder, a lentidão e a corporeidade. Jacques (2012) explica que: 
Enquanto o urbanismo busca a orientação através de mapas e planos, a preocupação do errante estaria mais na desorientação, sobretudo em deixar de lado seus condicionamentos urbanos, uma vez que toda a educação do urbanismo está voltada para a questão do se orientar. Em seguida, pode-se notar a lentidão dos errantes, como uma qualidade de movimento dos homens lentos, que negam o ritmo veloz imposto pela contemporaneidade. E, por fim, a própria corporeidade destes, e, sobretudo, a relação, ou contaminação, entre seu próprio corpo físico e o corpo da cidade que se dá através da ação de errar pela cidade. A contaminação corporal leva a uma incorporação, ou seja, uma ação imanente ligada à materialidade física, corporal, que contrasta com uma pretensa busca contemporânea do virtual e do imaterial. Esta incorporação acontece na maior parte das vezes quando se está perdido e em movimento do tipo lento (p. 59).

Quando o ato de perceber a cidade se torna um exercício constante, o olhar, um movimento silencioso, passa a descrever as nuances estéticas e funcionais, intrínsecas ao espaço, e através de um julgamento de valor ou juízo de apreciação questiona a sensibilidade, constituindo-se condição para entender o lado oculto da cidade, muitas vezes invisível aos cidadãos (Paiva, 2012).

A experiência errática da cidade, como possibilidade de experienciar a alteridade urbana, e as narrativas dessa errância, como sua forma de transmissão, podem operar como um potente desestabilizador das partilhas hegemônicas inerentes às relações sociais e das atuais configurações anestesiadas dos desejos dos indivíduos.

Essa relação corporal com a cidade mostra de forma crítica o cotidiano da espetacularização e explicita as tentativas de enfraquecer as experiências urbanas da alteridade (Jacques, 2012). Manifestam-se por meios artísticos, literários, etnográficos, cinematográficos ou cartográficos dentro de um cenário que vai contra os preconceitos e estereótipos no pensamento urbanístico.

Apropriar da cidade, portanto, é uma ação de transformação que consiste em comportamentos de territorialidade, a demarcação de um espaço, por exemplo, é uma necessidade inerente ao ser humano de assegurar seus direitos. Mas existe também a apropriação através da identificação que remete aos "processos simbólicos, cognitivos, afetivos e interativos que transformam o espaço (extensão) em lugar reconhecível e pleno de significado para o sujeito ou grupo social" (Cavalcante \& Elias, 2011, p. 66).

Através do exposto podemos identificar dois pontos de convergência com a atividade de design. Primeiramente, essa experiência vai além de conhecer lugares e pessoas, ela é uma forma de se mostrar as dificuldades e os problemas desses lugares e dessas pessoas. Por ser um exercício empírico, o designer se envolve de forma mais profunda e as ligações de contato que são estabelecidas podem ser tornar motivações para projetos de intervenção. Entre o que se conhece de uma cidade concebida e uma cidade vivenciada existem lacunas que outros métodos de reconhecimento não alcançam. Com isso, o design e o designer podem evoluir para uma prática projetual mais sistêmica, conforme exemplos a seguir. 


\section{Calafate, projeto Coletivo Micrópolis}

O Coletivo Micrópolis é um grupo de atuação, desde 2010, nas áreas da arquitetura e urbanismo, da pedagogia, de ação cultural e do design, norteados pela prática de transformação do espaço urbano. Não possuem um financiamento público ou privado, mas através de parcerias com a prefeitura de Belo Horizonte, cidade residente, e com iniciativas privadas conseguem intervir com propostas artísticas e urbanísticas (objeto construído) em pequena escala, trabalhando sempre as particularidades e identidades locais que apontem novas possibilidades de engajamento da comunidade e a transformação do espaço. O projeto Calafate foi uma intervenção do grupo, ocorrida em 2014 com o objetivo de fomentar para a população local a apropriação individual e coletiva do espaço público, delineado por duas diretrizes norteadoras, a democratização do uso do bairro Calafate, Belo Horizonte, e a identidade urbana. Constatou-se um processo de afastamento da comunidade nos locais comuns, como as praças e as ruas. Atritos entre mobilidade, interatividade, apropriação, vazios urbanos e outros usos demonstraram a necessidade de revisão dos métodos para a gestão pública do bairro.

É interessante ressaltar que essa necessidade é exposta e observada no documentário A Escala Humana (2013), do arquiteto dinamarquês Jan Gehl, ao afirmar que "ninguém sabia que o jeito que construímos as cidades tinha influência no modo de vida das pessoas". A referência da escala humana tornou-se um direcionamento para análise das potencialidades de convivência, bem como os fatores isolantes da interação social urbana, com o objetivo de entender o planejamento urbano através das pessoas que utilizam a cidade. É uma abordagem empática de projeto.

O projeto fundamentado a partir de três processos coerentes com a prática projetual do design manteve um alinhamento sistêmico em suas fases: observação e adaptação ao local, convivência e proposta de intervenção, conforme exposição da equipe diante da estrutura do trabalho:

Nossa inserção no Calafate buscou exercitar, desde o início, meios de infiltração e envolvimento que permitissem uma visão otimista do território e, em vez de identificar mazelas a serem resolvidas, despertassem possibilidades a serem fomentadas. O diagnóstico foi substituído pelos mapeamentos processuais, e os questionários tendenciosos, por ocasiões banais que suscitam conversas. Estruturamos nossa metodologia de imersão no bairro em três momentos [...]. Eles não estão divididos cronologicamente, nem hierarquicamente, mas são simultâneos, de modo a possibilitar interferências entre si. O que os diferencia é o limiar entre o caráter investigativo e o propositivo. Isto é, são aplicados ora para nos informar, ora para ativar transformações no bairro. É claro que qualquer observação, por mais discreta que seja, constitui em si mesma um elemento transformador do espaço. Ao mesmo tempo, toda ação concreta traz algum aprendizado sobre o lugar (Micrópolis, 2014a).

Compreendemos, mesmo não explicitado pela equipe, que durante o processo investigativo houve o envolvimento com a experiência da alteridade e essa imersão como método 
contrário aos questionários e entrevistas estruturadas buscou estabelecer um diálogo e uma narrativa detalhada da vivência urbana coletiva (Esquema 1).

Esquema 1 - Fases do projeto Calafate, Micrópolis.

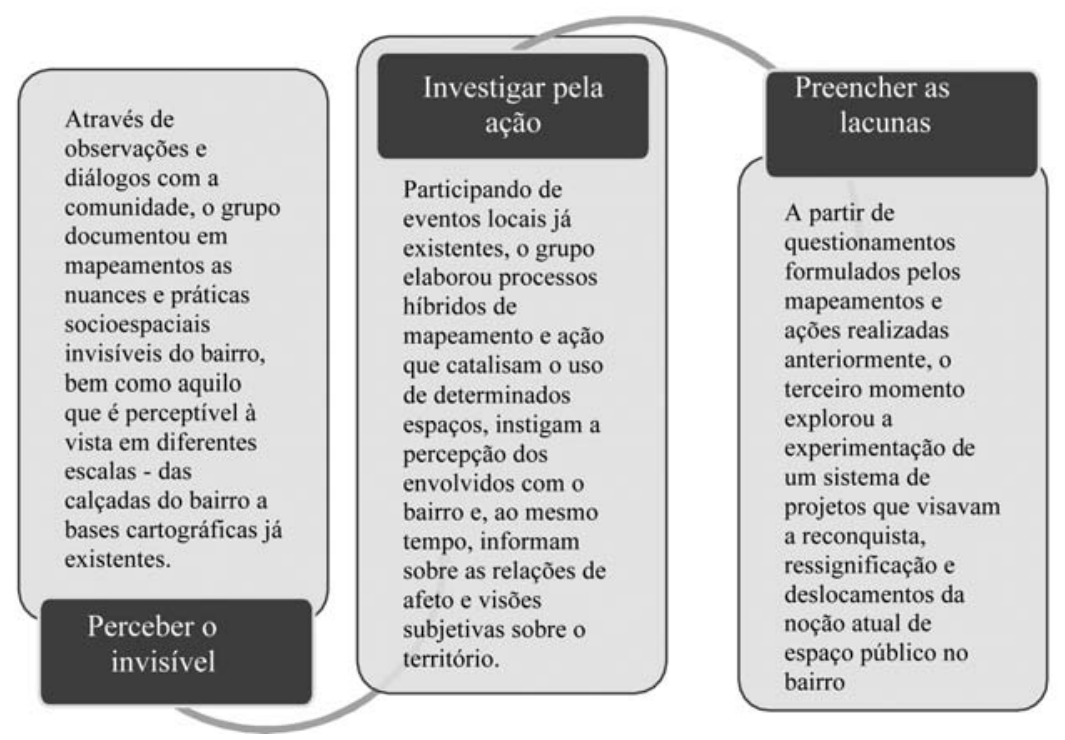

Fonte: adaptado de Micrópolis, 2014b².

As intervenções urbanas são direcionadas para uma experiência estética (num primeiro momento) com o propósito de estabelecer novas formas de perceber o cenário urbano e fomentar diferentes níveis de interação (físico, afetivo, emocional, cognitivo) com a cidade. Dessa forma, torna-se possível distanciar-se da objetividade funcional que envolve o cotidiano.

O Coletivo Micrópolis identificou no bairro Calafate quatro potenciais propostas de intervenção para retomada das práticas realizadas na rua pelos moradores: cinema, escola, jornal e praça, explicitados no livro gerado após o trabalho desenvolvido no bairro. A decadência do uso da rua, dos espaços públicos do bairro pode ser explicada pelo fator insegurança. O grupo identificou que os residentes desenvolveram resistência quanto a importância da participação cidadã e do diálogo para a apropriação e gestão de hábitos, usos e consumos coletivos que fortalecem a sustentabilidade do espaço público. 
Quando a intervenção urbana é efetiva, ela retoma ou expressa valores de identidade local, resgate da memória e o sentimento de pertencimento ao local, responsável por criar vínculos do usuário com o local em que está inserido.

A sensação de "pertencimento" significa que precisamos nos sentir como pertencentes a tal lugar e ao mesmo tempo sentir que esse tal lugar nos pertence, e que assim acreditamos que podemos interferir e, mais do que tudo, que vale a pena interferir na rotina e nos rumos desse tal lugar (Amaral, 2006, Seção Pertencimento, para. 5).

De acordo com Elali e Medeiros (2011), o uso que se faz do espaço físico interfere nos comportamentos que ali ocorrem. Em consequência, tal uso pode influenciar as respostas emocionais. As referências culturais e individuais que os indivíduos acumulam cotidianamente são frequentemente associadas com o meio de convivência, diante das diferentes situações em que se encontram. As características do ambiente físico propiciam o envolvimento social cotidiano. Essa relação ao conectar cognitiva e afetivamente pessoas e ambientes, auxilia na definição da identidade pessoal e comunitária.

\section{Design, informação e sociabilidade}

As imagens publicitárias na cidade são formas efêmeras que impactam a vivência dos cidadãos e através da propagação do consumo fomentam a inserção social segregativa. Para muitos indivíduos a experiência de habitar o espaço urbano é um exercício de visibilidades e invisibilidades. Forças comerciais desempenham o objetivo de tornar visível e selecionado o que é interessante consumir em detrimento de permanecer invisível o que não se caracteriza potencialmente consumível. Essa orientação comercial modifica os sentidos de pertencimento dos indivíduos, na medida em que delimita as condições de uso e acesso e deforma o sentido do espaço público.

Silva (2000) aponta que as forças de poder fomentam o acesso privilegiado dos grupos sociais através da afirmação da identidade em detrimento do que é diferente. Assim, o poder dita as diferenças que culminam em processos de inclusão e exclusão, visibilidade e invisibilidade. As diferenças classificam e normalizam os indivíduos. O consumo dos lugares na cidade evidenciam o poder e os acessos privilegiados. A característica pública de um espaço não abrange a possibilidade de uso democrático.

O mobiliário urbano também pode ser entendido como um elemento de segregação. Todo mobiliário urbano para fins públicos tem essencialmente a função democrática de uso e acesso. Mas a prática cotidiana traduz a configuração das identidades manifestadas pelas relações de igualdade e diferença. Ou seja, a função do objeto se espelha no contexto em que está inserido. Desde 2015, a cidade de Belo Horizonte vem implantando as varandas urbanas ao lado da calçada de bairros de classe média à alta. O mobiliário ocupa a vaga de dois carros, instalado e mantido por comerciantes e de livre acesso aos transeuntes, sem 


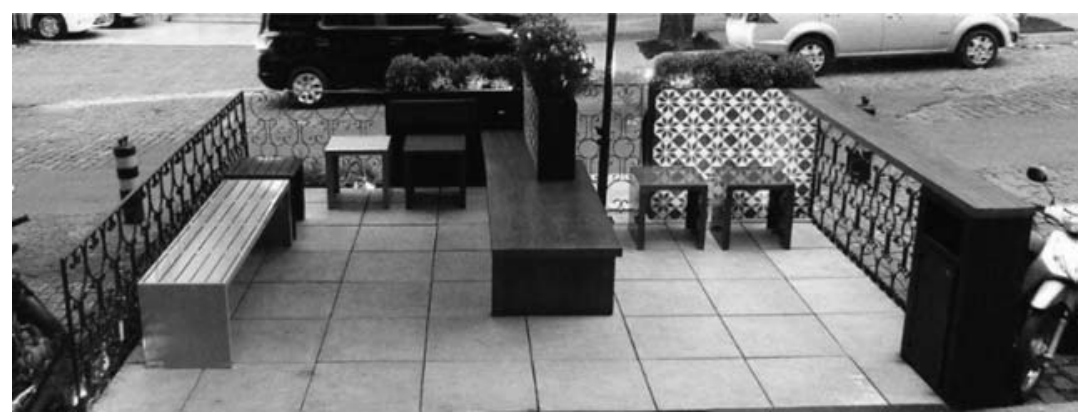

Figura 2. Varanda urbana em Belo Horizonte. Fonte: https:/www.soubh.com.br/noticias/viva-bem/ parklets-bh

ligação direta com os estabelecimentos. A proposta com viés de uso público visa potencializar os pontos de encontro e os momentos de descanso e lazer.

Manifestações mais democráticas através do objeto podem ser percebidas no projeto da plataforma modular do escritório de arquitetura italiano - Piuarch - desenvolvido para a cidade de São Paulo. Foi instalado no espaço externo do Circuito CEU na favela de Paraisópolis. Constituído por módulos, que o torna versátil aos usos, além de envolver as pessoas no processo de valorização do espaço e o sentido da coletividade.

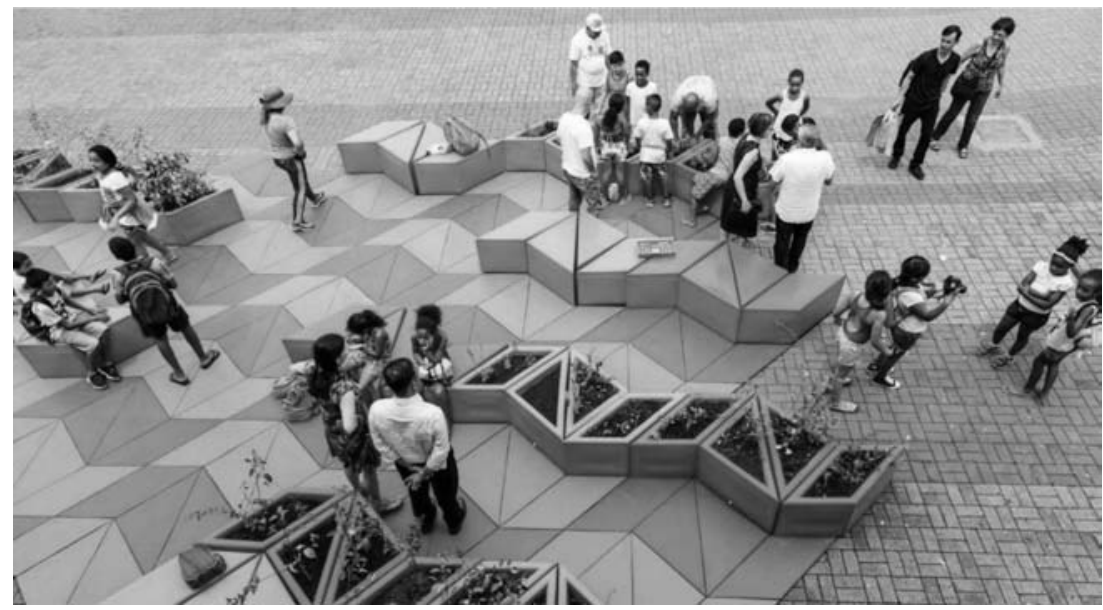

Figura 3. Espaço, mobiliário versátil e modular do escritório Piuarch. Fonte: https://www.piuarch.it/ en/projects/espaco 
No que tange a qualificação do mobiliário urbano para fins democráticos Brandão (2002 como citado em Paiva, 2012, p. 68) classifica os atributos de avaliação para o uso apropriado do objeto. Categorizamos esses atributos por afinidades, onde os conceitos são complementares e dialogam na definição da qualidade do objeto proposto para o uso diversificado, integrado e responsável no espaço público urbano. Os conceitos que ora se complementam, ora se opõem formatam a complexidade atribuída a funcionalidade do mobiliário urbano.

Esquema 2 - Atributos de uso do objeto.

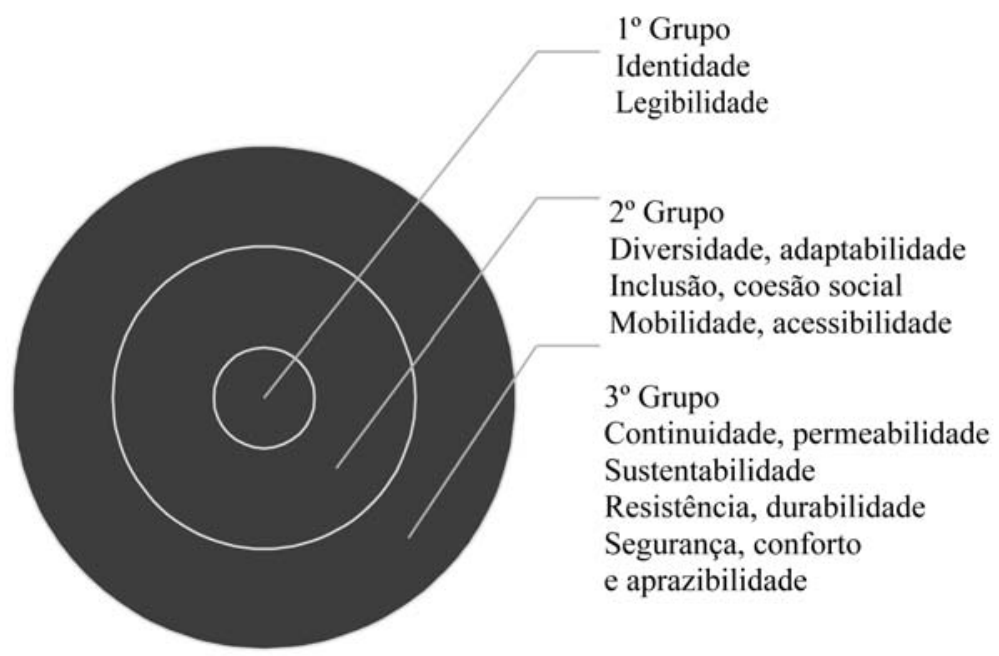

Fonte: adaptado de Paiva (2002) pelos autores, 2019.

De acordo com o autor, o primeiro grupo refere-se ao alinhamento das características locais e contextuais do ambiente de inserção do objeto, podendo elas serem históricas, materiais, naturais e culturais, de tal forma que a compreensão função-forma aconteça de maneira rápida, clara e identificável ao lugar. Ao mesmo tempo, é necessário haver as características do segundo grupo, que retrata a importância das conexões entre objeto lugar - usuário. Legíveis e acessíveis, conexão do objeto com o lugar, mas permitindo a diversidade de usos e pessoas são caminhos possíveis, porém complexos. O autor expõe que através da coesão social é possível amenizar e eliminar a marginalização e restrição 
social. Para enfatizar esses elementos é importante tangibilizar a segurança, o conforto e a sustentabilidade, conforme exposto no terceiro grupo, de acordo com potencialidade físicas que caracterizam a função-forma, qualidade dos materiais adequada às características ambientais, conservação e intensidade de uso.

\section{Borrachalioteca Sobre Rodas (B.S.R.), projeto do grupo de pesquisa Design e Representações Sociais}

O projeto Borrachalioteca Sobre Rodas (B.S.R.) foi desenvolvido pelo Grupo de Pesquisa Design e Representações Sociais da Universidade do Estado de Minas Gerais (UEMG), financiado pelo CNPq. O projeto objetivou criar uma ferramenta que possibilitasse a inserção à leitura a partir da criação de um veículo que permitisse o deslocamento das ações Borrachalioteca na cidade de Sabará, um projeto misto de borracharia e biblioteca que atende as camadas mais populares emprestando livros e promovendo ações culturais.

A Borrachalioteca foi o objeto de pesquisa para exemplificar como a cultura e os valores da comunidade trazem identidade ao ambiente, como o design pode auxiliar na identificação da identidade local reforçando-a e criando um senso de pertencimento e orgulho nos seus usuários.

Na contemporaneidade o design tem configuração diversa, com inúmeras possibilidades de relações e associações. É uma grande rede, um tecido entrelaçado e articulado, repleto de significações resultantes do entrelaçamento e articulação de signos que geram linguagens diferenciadas. Essa grande rede flexível atua na esfera da informação, comunicação e conhecimento, tem como foco central o homem, as dinâmicas e produções culturais que o envolvem (Moura, 2011, p. 89).

O projeto "Borrachalioteca" criado por Marco Túlio Damascena, começou sem maiores pretensões há, aproximadamente, 18 anos, na cidade de Sabará, Minas Gerais, Brasil. Do lado da borracharia do seu pai, o espaço foi aos poucos tomando forma, e dessa união se deu a origem do nome - borracharia com biblioteca, que, desde o seu surgimento denotava a intenção do criador em formar mais leitores e proporcionar acesso aos livros de uma forma descontraída e despretensiosa.

No ano de 2014 a proposta era abrir vários cursos de envolvimento com a comunidade e fora dela. Cursos de palhaço, de teatro com dança, canto e recitar poemas. A Borrachalioteca participava com o "Arautos da Poesia", grupo de jovens frequentadores do espaço, de apresentações recitando poemas em várias cidades de Minas Gerais, com o objetivo de levar a leitura e o encanto de se recitar poesias e prosas, incentivando jovens e adultos à participação cultural. No entanto, o deslocamento de materiais para as atividades era feito de maneira precária, assim como o palco para suas apresentações.

Assim, a B.S.R. foi concebida para auxiliar o projeto da Borrachalioteca a se locomover pelas diversas cidades no entorno de Sabará e região. Foi projetada para ser acoplada ao 
veículo automotivo de forma simples e eficaz. O conceito da B.S.R. é baseado na cultura cigana, inclusive na forma da carenagem, com o teto em semicírculo (abaulado). Seu desenho aponta como asas abertas nas laterais que insinuam o voo para o conhecimento através da leitura. Seu material em chapa de aço carbono e estrutura em metalon configuramno como resistente a chuva e intempéries. Possui as prateleiras de MDF com revestimento melamínico. As prateleiras foram projetadas para transportar os livros da Borrachalioteca e no espaço interno para transportar outros objetos como cadeiras e pufes, convidando as pessoas a se sentarem para ler um livro ou um cordel. O projeto do produto conta com a autoria do designer Anderson A. Horta e o projeto gráfico do designer Sérgio L. da Silva.
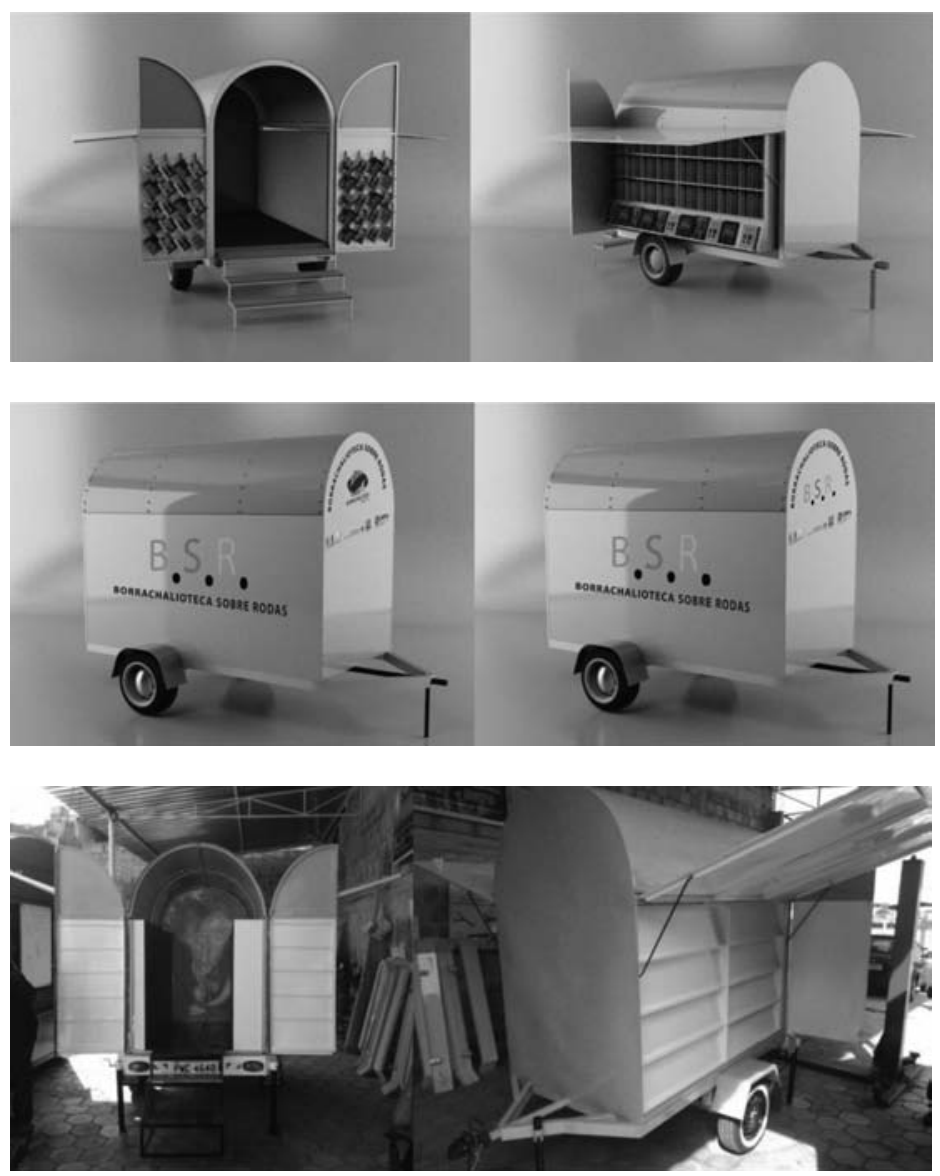

Figura 4 (acima). Borrachalioteca Sobre Rodas (protótipo). Fonte: HORTA, 2015. Figura 5 (centro). Borrachalioteca Sobre Rodas (protótipo gráfico). Fonte: HORTA, 2015. Figura 6 (baixa). Borrachalioteca Sobre Rodas. Fonte: HORTA, 2015. 
A Borrachalioteca Sobre Rodas obteve êxito em sua inauguração em dezembro de 2015 no Festival de Jabuticaba de Sabará.. Desde então a B.S.R. tem sido levada para várias comunidades periféricas da cidade de Sabará e fora dela. A possibilidade de deslocamento dos livros e materiais proporciona momentos de leitura ao ar livre, com apresentações do grupo de poesia e doações de livros, levando os hábitos de leitura e promovendo entretenimento sociocultural a regiões distantes da sede física. Assim, com este projeto, o design pode e deve cruzar as fronteiras dos objetivos puramente comerciais, voltando-se para práticas de apoio social, como acontece com a BSR.

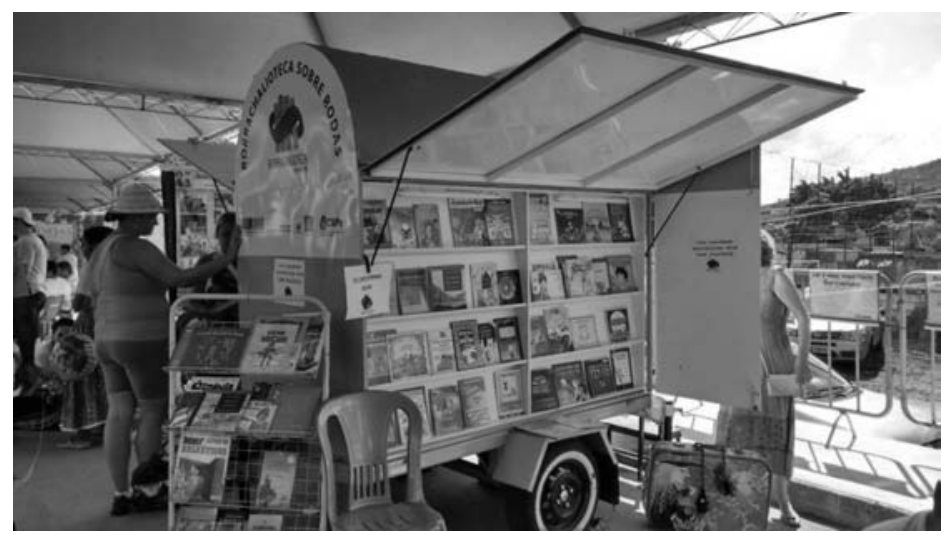

Figura 7. Borrachalioteca Sobre Rodas. Fonte: Lins, 2015.

O projeto conseguiu atingir a demanda na facilidade do transporte dos livros até os eventos bem como a exposição e o convite para a comunidade. "O que temos aqui são pessoas que gostam de ler e se sentem à vontade com esse momento. Muita gente diz que brasileiro não gosta de ler e aqui vemos que isso não é verdade. Aqui está cheio de gente o dia todo.” Diz Luciane, uma das organizadoras da Borrachalioteca. Dessa forma, vê-se a necessidade de mais projetos e eventos que fomentem cada vez mais iniciativas como estas, que possam envolver toda a comunidade no intuito de valorização dos hábitos culturais, propiciando uma sociedade mais crítica e engajada.

A conexão entre pesquisa e execução de um produto palpável que beneficia a melhoria da qualidade de vida das pessoas, comprova que o design pode e deve ser um agente de transformação social, trazendo impactos positivos promovendo a cidadania. 


\section{Considerações finais}

Fomentar espaços democráticos não é tarefa fácil para o design e as áreas transversais - Arquitetura e Urbanismo, Gestão Pública, Geografia, Ciências Sociais e afins. Como em qualquer ambiente de gerenciamento, o espaço público urbano também precisa de diagnósticos que apontem as oportunidades e as ameaças, as forças e as fraquezas, no que tange ao exercício democrático do convívio social. Muito se fala dos limites da atuação do Design, e nesse meio crescem também os diálogos e conexões com o planejamento urbano e a humanização da cidade.

O planejamento tradicional da cidade, atrelado aos paradigmas socioculturais e comportamentais vigentes na sociedade contemporânea, promove a desigualdade social quanto ao acesso e uso desses espaços. Este trabalho pretendeu investigar a contribuição do design, como agente transformador, na ênfase das potencialidades materiais do espaço público urbano para afirmar o direito à cidade. Entende-se que a construção do movimento de apropriação urbana converge com práticas de design, a qual se apoia num pensamento humanista capaz de tangibilizar linguagens e identidades locais.

O Design como ferramenta ou instrumento para promover a integração do indivíduo em seu meio social, é um fenômeno de linguagem, uma vez que através da comunicação e informação acessível pode influenciar comportamentos e suscitar novos significados para o espaço urbano. A partir de referências globais e ações a nível local, de forma a trabalhar a valorização da identidade e cultura de cada lugar, opondo-se às políticas públicas que neutralizam a vivência urbana. É uma abordagem voltada para a cidade real, e não para a cidade ideal fomentada por um processo de espetacularização urbana, através de projetos de assepsia urbana, gentrificação, vigilância e controle urbano. Dialoga, portanto, com as rupturas do cotidiano, perturbando a rotina, modificando a usabilidade e o consumo no espaço urbano com foco na sustentabilidade social da cidade.

Espera-se com o presente trabalho incitar a reflexão dos atuais paradigmas socioculturais e comportamentais que colaboram para a segregação no convívio do espaço público urbano; dos atuais diálogos sobre o planejamento urbano e a humanização da cidade; quanto à afirmação do direito à cidade, impulsionando assim, a continuidade do estudo do tema na área do design.

Cabe aqui ressaltar que, mesmo com a relevância do papel do design para a problemática urbana atual, percebe-se pouco aprofundamento teórico e capacitação dos profissionais que abordam a temática do Design e Cidadania. É um campo novo de atuação do designer, sobretudo no Brasil, e, portanto, seu estudo necessita ser ampliado, considerando a tendência de crescimento em pesquisas sobre o futuro e a transformação das cidades. Este artigo teve o apoio da FAPEMIG, CAPES e CNPq.

\section{Notas}

1. Calafate, Coletivo Micrópolis. Trabalho de Conclusão de Curso de Belisa Murta, Felipe Carnevalli, Marcela Rosenburg, Matheus Lira e Vítor Lagoeiro, sob a orientação de Adria- 
no Mattos, Ana Paula Baltazar, Natasha Rena, Roberto Andrés e Wellington Cançado. Escola de Arquitetura UFMG. Belo Horizonte, 2014.

\section{Bibliografia}

A Escala Humana. Direção: Andreas Møl Dalsgaard. Produção: Signe Byrge Sørensen. Dinamarca: Final Cut for Real, 2013. (77 min). Documentário. Versão em espanhol: La Escala Humana, disponibilizada pela Elche Dinámico EFDEC. Recuperado em 18 outubro, 2017, de https://www.youtube.com/watch?v=zkFgt80DUwU

Amaral, A. L. (2006). Pertencimento. Dicionário de Direitos Humanos. Recuperado em 17 fevereiro, 2019, de http://escola.mpu.mp.br/dicionario/tiki-index.php?page=Pertencimento

Andrade, P. S.; Barros, R. Q. de; Lins, W. G. \& Wanderley, M. L., Jr. (2017). Bases comuns do design: uma discussão sobre o impacto e papel social do design. em A. J. V. Arruda (Org) Design \& Complexidade. São Paulo: Blucher. Recuperado em 31 janeiro, 2019, de https:// openaccess.blucher.com.br/article-details/bases-comuns-do-design-20243

Bonsiepe, G. (2011). Design, cultura e sociedade. São Paulo: Blucher.

Borrachalioteca de Sabará. Recuperado em 17 fevereiro, 2019, de http://borrachalioteca. blogspot.com.br

Carvalho, S.; Castela, S. de \& Oliveira, E. de. (2007-2008). Experiência no espaço público. Lisboa: DCiii. Recuperado em 12 maio, 2017, de http://areas.fba.ul.pt/in2places/images/ objecto_sustentacao.pdf

Castriota, L. B. (2010). Vivências efêmeras, lugares sem peso: a estetização nas cidades contemporâneas. ComCiência versão online, Campinas (122), pp. 0-0. Recuperado em 05 maio, 2018, de http://comciencia.scielo.br/scielo.php?script=sci_arttext\&pid=S1519$76542010000800011 \& \operatorname{lng}=\mathrm{pt} \& \mathrm{nrm}=\mathrm{iso}$

Cavalcante, S. \& Elias, T. F. (2011). Apropriação. In S. Cavalcante \& G. A. Elali (Orgs.).Temas básicos em psicologia ambiental. Petrópolis: Editora Vozes.

Celaschi, F. \& Moraes, D. de (2013). Futuro, bem-estar, interdependência: palavras-chave para o design contemporâneo. In F. Celaschi, \& D. De Moraes (Orgs.). Cadernos de Estudos Avançados em Design: Design e Humanismo (Vol. 7, pp. 35-60). Barbacena: EdUEMG.

Elali, G. A. \& Medeiros, S. T. F. de. (2011). Apego ao lugar (vínculo com o lugar - place attachment). In S. Cavalcante \& G. A. Elali (Orgs.). Temas básicos em psicologia ambiental. Petrópolis: Editora Vozes.

Harvey, D. (2014). Cidades rebeldes: do direito à cidade à revolução urbana. São Paulo: Martins Fontes - selo martins.

Jacques, P. B. (2012). A experiência errática da cidade: em busca da alteridade urbana. em A. C. T. Ribeiro, M. L. P. da Silva, \& L. F. Vaz (Orgs.). Leituras da cidade (pp. 48-64). Rio de Janeiro: Letra Capital: ANPUR. Recuperado em 31 janeiro, 2019, de http://www.anpur. org.br/publicacao/arquivos/leituras-da-cidade.pdf

Latour, B. (2014). Um Prometeu cauteloso? alguns passos rumo a uma filosofia do design (com especial atenção a Peter Slotedijk) (I. Fraga, \& D. B. Portugal, Trad.). Palestra para o encontro Networks of Design, da Design History Society. Falmouth, Cornua- 
lha, 3 de setembro de 2008. Agitprop Revista Brasileira de Design, 6(58). Recuperado em 12 fevereiro, 2019, de http://www.agitprop.com.br/index.cfm?pag=repertorio_ $\operatorname{det} \& i d=86 \&$ Titulo $=$ repertorio

Micrópolis. Projeto Calafate. (2014a). Recuperado em 17 fevereiro, 2019, de https://www. micropolis.com.br/Calafate-1

Moura, M. (2011). Interdisciplinaridades no Design Contemporâneo. In: M. dos S. Menezes, Moura, M. \& Paschoarelli, L. C. (Orgs.). Metodologias em design: inter-relações (pp. 274-290). São Paulo: Estação das Letras e Cores. Recuperado em 31 agosto, 2019, de https://www. academia.edu/4880345/Interdisciplinaridades_no_Design_Contempor\%C3\%A2 neo

Nogueira, P. C. E. \& Portinari, D. B. (2016). Por um design político. Estudos em Design Revista Online, 24(3), 32-46. Recuperado em 12 fevereiro, 2019, de https://estudosemdesign. emnuvens.com.br/design/article/view/379/255

Paiva, B. A. F. (2012). Design e urbanidade: cumplicidades do Programa Polis. Tese de doutorado, Universidade Técnica de Lisboa, Faculdade de Arquitetura, Lisboa, Distrito de Lisboa, Portugal.

Silva, T. T. da. (2000). A produção social da identidade e da diferença. In S. Hall, T. T. da Silva (Org.) \& K. Woodward. Identidade e diferença: a perspectiva dos estudos culturais (pp. 73-102). Petrópolis: Vozes.

Resumen: La participación ciudadana en el espacio público urbano puede ser explotada por la actividad del diseño, contraponiéndose a la manipulación de fuerzas dominantes que modelan la usabilidad de las ciudades y crean patrones segregados. Los diseñadores, conscientes de su responsabilidad social ya través de una visión humanista, modifican el arreglo espacial y el sentimiento de pertenencia de los individuos, es decir, objetos, mensajes, sistemas y experiencias se configuran como potencializadores de la dinámica del cotidiano urbano y de la afirmación del derecho la ciudad. El presente artículo explora el concepto experiencia de la alteridad como un camino o inspiración que intercede a las prácticas de diseño, siendo estas prácticas explotadas en este trabajo por la actuación del Colectivo Micrópolis, en proyecto de intervención en el barrio Calafate, Belo Horizonte, Brasil, en el breve análisis del presente, el impacto de las instalaciones de balcones urbanos en las calles y aceras de la ciudad, en el que se describen atributos dirigidos al uso de mobiliario inclusivo y descripción de diseño de diseño, titulado Borrachalioteca Sobre Rodas (BSR), divulgado e implementado para la comunidad de Sabará, Brasil. La intención de este trabajo es incitar a la reflexión de los actuales diálogos sobre la vivencia y la humanización de la ciudad.

Palabras clave: diseño - espacio urbano - derecho a la ciudad - experiencia - intervenciones.

Abstract: Citizen participation in urban public space can be exploited by design activity, counteracting the manipulation of dominant forces that model city usability and create segregation patterns. Designers, conscious of their social responsibility and through a hu- 
manistic vision, modify the spatial arrangement and the sense of belonging of the individuals, that is, objects, messages, systems and experiences are configured as potentialists of the dynamics of urban everyday life and the affirmation of the right the city. The present article explores the concept of alterity as a path or inspiration that intercedes the design practices, being these practices explored in this work by the action of the Micrópolis Collective, in an intervention project in the Calafate neighborhood, Belo Horizonte, Brazil, in the brief analysis of the impact of urban balconies on the streets and sidewalks of the city, which describes attributes directed to the use of inclusive furniture and description of design project, called Borrachalioteca Sobre Rodas (BSR), published and implemented for the community of Sabará, Brazil. The purpose of this work is to stimulate the reflection of the current dialogues about the experience and the humanization of the city.

Keywords: design - urban space - right to the city - experience - interventions.

[Las traducciones de los abstracts fueron supervisadas por el autor de cada artículo] 